\title{
Safe and economical use of hemostatic forceps for dissecting fibrosis or vessels during endoscopic submucosal dissection
}

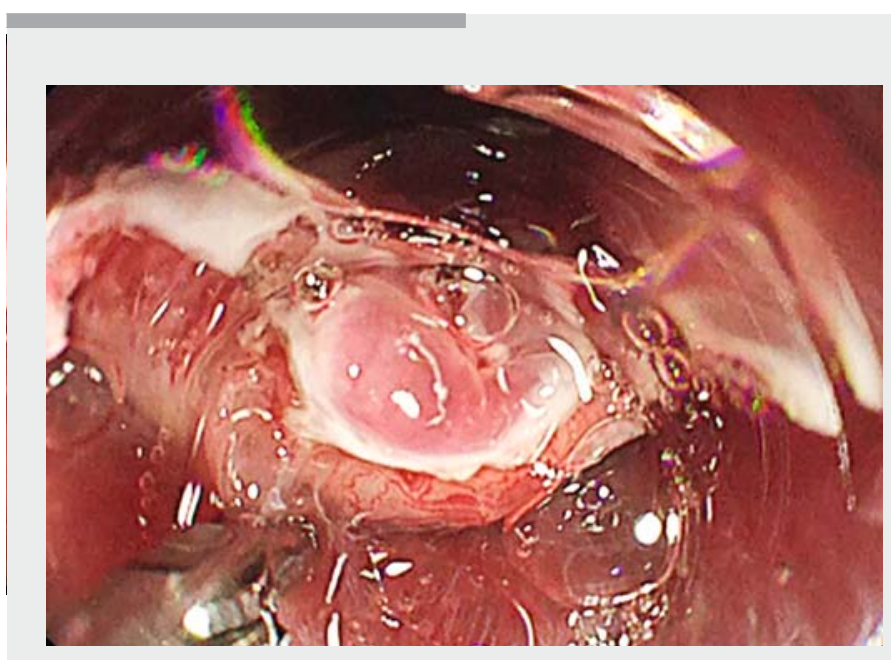

$\checkmark$ Video 1 New application of HF using incisional mode is cost-effective and useful for completing ESD easily and safely.

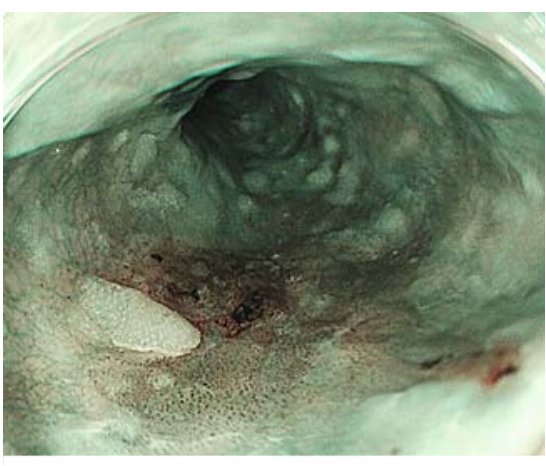

- Fig. 1 Endoscopic view of an early esophageal carcinoma $(25 \times 20 \mathrm{~mm}$ in diameter) in the middle esophagus.
Endoscopic submucosal dissection (ESD) is a well-established therapeutic strategy for resecting early gastrointestinal neoplasms[1-3]. However, operators sometimes encounter difficult situations during ESD, resulting in longer procedure times and an increasing complication rate. The more complicated situations involve encountering the muscularis propria (MP) and submucosal fibrosis, managing large or rich vessels, and resecting the endpoint. In these situations, a device such as a scissors type of knife

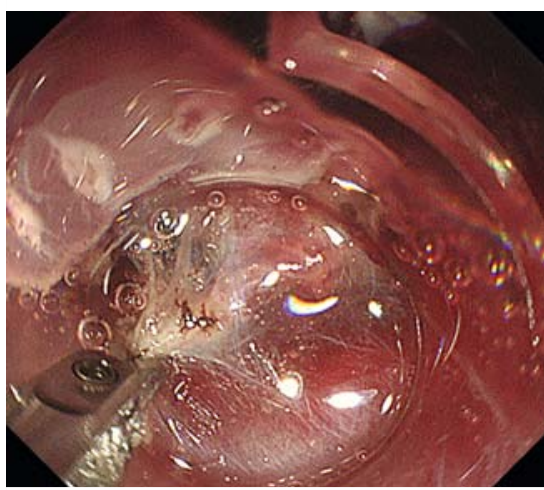

- Fig. 2 Large vessel in the submucosa coagulated using hemostatic forceps (HF) with soft coagulation.

[4] is sometimes introduced. However, use of a scissors type device in addition to a needle knife becomes uneconomical. Here we describe an effective incision using HF for overcoming the aforementioned difficulties in esophageal ESD ( $\triangleright$ Video 1$)$.

In this case, we used ESD for early esophageal carcinoma (\$ Fig.1). While proceeding with standard ESD, we noted submucosal fibrosis and large vessels. The vessels were coagulated using HF (Coagrasper, FD-411UR; Olympus, To-

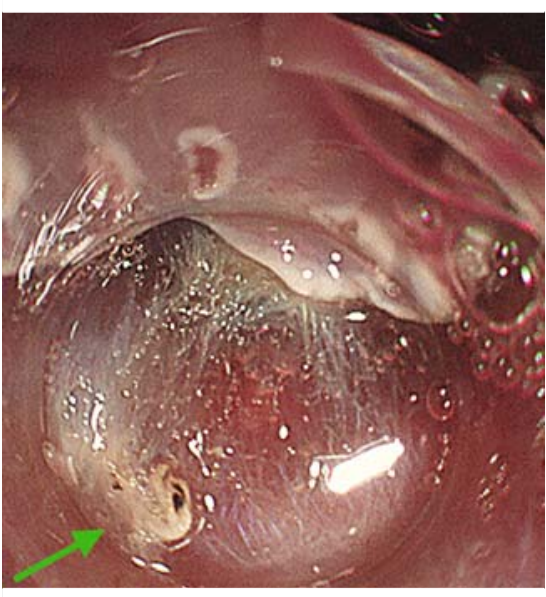

$\checkmark$ Fig. 3 Endoscopic view showing the vessel (green arrow) dissected without any bleeding using $\mathrm{HF}$ with Endocut mode.

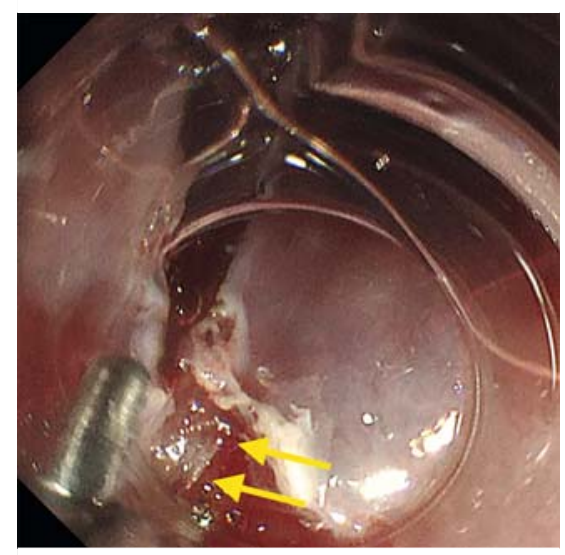

- Fig. 4 Endoscopic view showing safe cutting by HF of submucosa (yellow arrows) facing the muscle layer.

kyo, Japan) ( $\mathbf{F i g . 2}$ ) with soft coagulation (effect 4, 30 W) of the electric generator (VIO300D; ERBE, Tübingen, Germany), followed by dissection of the vessel and fibrosis using HF with the Endocut mode (effect 1, duration 2) (> Fig.3). This series of techniques led to a shortening of the procedure time. The HF was also effective in safe submucosal dissection when encountering the MP layer, which is at risk for perforation ( Fig.4). Our technique of using HF at the challen- 


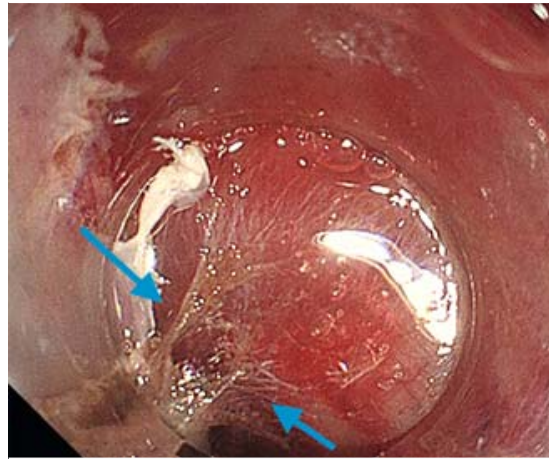

- Fig. 5 Endoscopic view showing effective resection by HF of the endpoint (blue arrows).

ging endpoint of ESD, in which the dissection is sometimes difficult due to the flexible movement of the resected lesion, can decrease the likelihood that the dissection will be difficult (> Fig.5). Finally, esophageal ESD was achieved without complications with the help of the incisional function of HF.

We suggest that our novel application of HF using the incisional mode is a useful and economical option for completing ESD easily and safely.
The authors declare that they have no conflict of interest.

The authors

Taiga Chiyo, Hideki Kobara, Noriko Nishiyama, Kazuhiro Kozuka, Nobuya Kobayashi, Shintaro Fujihara, Tatsuo Yachida, Tsutomu Masaki

Department of Gastroenterology and Neurology, Faculty of Medicine, Kagawa University, Kagawa, Japan

\section{Corresponding author}

Hideki Kobara, MD, PhD

Department of Gastroenterology and Neurology, Faculty of Medicine, Kagawa University, 1750-1 Ikenobe, Miki, Kita, Kagawa 761-0793, Japan Fax: +81-87-891-2158 kobara@med.kagawa-u.ac.jp
References

[1] Rey Ferro M. Endoscopic submucosal dissection tunneling technique for removal of a giant early esophageal squamous cancer involving $75 \%$ of the esophageal circumference. Endoscopy 2019; 51: E116-E117

[2] Hatta W, Gotoda T, Koike T et al. A recent argument for the use of endoscopic submucosal dissection for early gastric cancers. Gut Liver 2019: doi:10.5009/gnl19194

[3] Liu Q, Ding L, Qiu X et al. Updated evaluation of endoscopic submucosal dissection versus surgery for early gastric cancer: A systematic review and meta-analysis. Int J Surg 2020; 73: 28-41

[4] Kitagawa Y, Nankinzan R, Suzuki T et al. Endoscopic submucosal dissection using an SB Knife Jrwith clip traction method for esophageal cancer at the anastomotic site after total gastrectomy. Endoscopy 2019; 51: E143-E144

\section{Bibliography}

DOI http://dx.doi.org/10.1055/a-1191-1163

Endoscopy International Open 2020; 08: E1520E1521

Georg Thieme Verlag KG

Rüdigerstraße 14,

70469 Stuttgart, Germany

eISSN 2196-9736

(C) 2020. The Author(s).

This is an open access article published by Thieme under the terms of the Creative Commons Attribution-NonDerivative-NonCommercial License, permitting copying and reproduction so long as the original work is given appropriate credit. Contents may not be used for commecial purposes, or adapted, remixed, transformed or built upon. (https://creativecommons.org/licenses/by-nc-nd/4.0/) 